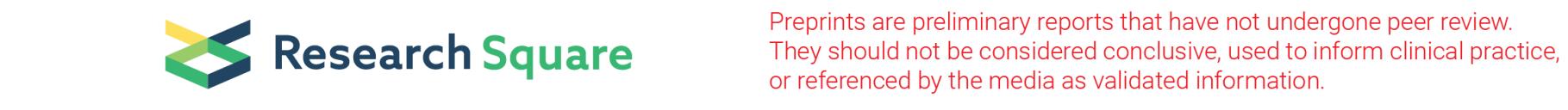

\title{
Predictors of Malnutrition among Pregnant Women in Ethiopia: Systematic Review and Meta-Analysis
}

Temesgen Getaneh ( $\nabla$ temugetaneh@gmail.com )

Debre Markos university https://orcid.org/0000-0002-5645-0006

Ayenew Negesse

Debre markos University

Research article

Keywords: Under nutrition, Burden, Pregnant women, Ethiopia

Posted Date: June 9th, 2020

DOI: https://doi.org/10.21203/rs.3.rs-34039/v1

License: @) (i) This work is licensed under a Creative Commons Attribution 4.0 International License. Read Full License

Version of Record: A version of this preprint was published at Human Nutrition \& Metabolism on August 1st, 2021. See the published version at https://doi.org/10.1016/j.hnm.2021.200131. 


\section{Abstract \\ Background}

Women of reproductive age are especially vulnerable to protein energy deficiency and under nutrition. Malnutrition is the underlying cause of significant maternal morbidity and mortality. In addition, malnutrition among women is a major risk factor for adverse birth outcomes. Its extent and consequences is highly prevalent in developing countries. This major burden can be reduced through effective nutritional interventions. So, up to date meager evidences were warranted. Therefore, this systematic review and meta-analysis was aimed to estimate the overall pooled prevalence of malnutrition and its predictors among pregnant women in Ethiopia.

\section{Methods}

Articles were systematically searched using PubMed, EMBASE, Google Scholar, World Health Organization's (WHO) Hinari portal data bases and institutional repositories. Newcastle-Ottawa quality assessment scale adapted for observational studies was applied. We used Stata version 14 for data analysis. Heterogeneity and publication bias were checked using $P$ statistic, funnel plot asymmetry and Egger's test. Random effect model was applied to estimate the pooled prevalence of malnutrition and its predictors. Odds Ratio (OR) with $95 \%$ Confidence Interval (Cl) was also considered to identify factors.

\section{Result}

24 eligible articles were included for final analysis. The average pooled prevalence of malnutrition among pregnant women in Ethiopia was $29.07 \%$ (95\% Cl: 24.84, 33.30). Maternal education $(\mathrm{OR}=1.60,95 \% \mathrm{Cl}: 1.01,2.53)$, income $(\mathrm{OR}=3.07,95 \% \mathrm{Cl}: 1.36,6.92)$, pregnancy intention $(\mathrm{OR}=1.33$, $95 \% \mathrm{Cl}: 1.01,1.37)$, number of meal $(\mathrm{OR}=4.63,95 \% \mathrm{Cl}: 3.00,7.15)$, dietary diversity $(\mathrm{OR}=2.89,95 \% \mathrm{Cl}: 1.28,6.53)$, antenatal care $(\mathrm{OR}=2.53,95 \% \mathrm{Cl}$ : $1.18,5.42)$ and iron supplementation $(\mathrm{OR}=0.63,95 \% \mathrm{Cl}: 0.45,0.88)$ were predictors of the pooled prevalence of malnutrition among pregnant women in Ethiopia.

\section{Conclusion}

Generally, significant number of pregnant women in Ethiopia were suffered from malnutrition. Maternal education, income, pregnancy intention, number of meal, dietary diversity, antenatal care and iron supplementation were significant predictors of malnutrition. Strategies targeting advocating women education, standard antenatal care, family planning utilization, and encouraging pregnant women to have good dietary diversity and frequent meal should be undertaken by Ministry of Health and its stake holders to handle this signficant budren of malnutrition among pregnant women.

\section{Background}

Today, nearly one in three persons globally suffers from at least one form of malnutrition [1]. Women of reproductive age are especially vulnerable to chronic energy deficiency and other malnutrition [2, 3]. Globally, approximately $13 \%$ of women were estimated to be undernourished [4, 5]. Maternal and child malnutrition is the underlying cause of 3.5 million deaths [6]. The main nutritional issues impacting pregnant women were protein and energy under nutrition and deficiencies of micronutrients, such as iron, folate, calcium, vitamin D and vitamin A [7, 8]. Globally, 38\% of all pregnant women suffered from anemia and contributing for $20 \%$ of maternal mortality [9]. Pregnancy increases the risk of iron deficiency anemia as there is an increase in maternal iron requirements [10]. Around $70 \%$ risk of anemia can be reduced through iron supplementation during pregnancy [11].

In addition, malnutrition among pregnant women is a major risk factor for adverse birth outcomes [12]. It will increase risks of prematurity, small for gestational age, neural tube defect, intrauterine growth restriction, low birth weight and a weakened immune system [13-15]. Furthermore, evidences showed these children were suffered from long term consequences like insufficient cognitive development, glucose metabolism abnormality and impaired body system functions $[12,16,17]$. This global burden of malnutrition had developmental, economic, social and medical impacts for individuals, families, communities and countries as a whole [18].

The extent and consequences of malnutrition among pregnant women is highly prevalent in developing countries particularly in Sub Saharan Africa (SSA), resulting in substantial increases in disease burden and mortality $[19,20]$. This may be due to poverty, low dietary intake, inequitable distribution of food within the household, food insecurity, dietary taboos, frequent infectious diseases and suboptimal care practices [7, 8]. Subsequently, obstetric complications and adverse birth outcomes are common in this region [21]. According to Ethiopian Demographic Health Survey (EDHS) 2016, 22\% of women were under nutrition and $24 \%$ were anemic in Ethiopia. In addition, $24 \%$ of children under age 5 are underweight, $38 \%$ of children are stunted and $10 \%$ are wasted in Ethiopia [22].

Page 2/19 
Optimal maternal nutrition is an important contributor to the survival of mother and a critical step towards the reduction of infant mortality and morbidity and reduction of the emerging metabolic and cardiovascular diseases in adulthood [9, 20]. The World Health Assembly endorsed a Comprehensive implementation plan on maternal nutrition for 2025. This major reduction in burden of under nutrition can be made through programmatic health and cost effective nutritional interventions and policies [23]. This will have a contribution to achieve the Sustainable Development Goals (SDGs) of ending all forms of malnutrition and ensuring healthy lives and well-being for all at all ages [24].

In Ethiopia, to accelerate the reduction of malnutrition, in 2016 Ethiopia government developed the national nutrition programme II and the national guideline on adolescent, maternal, infant and young child nutrition [22]. So, for implementing such interventions, up to date meager evidences is warranted. Several fragmented individual studies were done in Ethiopia to assess nutrition status and associated factors among pregnant women. From these studies, the lowest and highest prevalence under nutrition were $11.6 \%$ and $47.2 \%$ respectively in which both reported in Oromo region $[25,26]$.

In addition, these individual studies also stated factors like maternal age, income, residence, marital status, educational status, women decision, substance abuse, water source, toilet possession, family size, dietary diversity, number of meal, dietary advice, family planning, pregnancy intention, antenatal care follow up, parity, gestational age, any illness and iron supplementation as a potential associated factors with malnutrition during pregnancy even though inconsistent findings were recorded [27-35]. Therefore this systematic review and meta-analysis was done to estimate the pooled burden of malnutrition and its predictors among pregnant women in Ethiopia.

\section{Methodology Searching strategies}

At first, predictors of malnutrition among pregnant women in Ethiopia: systematic review and meta-analysis was searched from Prospero to avoid duplication. Systematic review and meta-analysis similar to this title was not done before this. Using headings and combined key words, studies were systematically searched on major medical electronic databases. Databases such as PubMed, Medline, EMBASE, Cochrane library, web of science World Health Organization's Hinari portal (which includes the SCOPUS, African Index Medicus, and African Journals Online databases), Google and Google Scholar were used to dig out relevant articles for this review. In addition, the cross references (lists of already identified articles references), academic and governmental institution online library, grey literature available on local shelves and organization websites were used to access un-published articles. All data bases were searched till March 2020. The database search results were exported to EndNote citation manager software (version X7; Thomson Reuters, New York, NY) and duplicate articles were removed. The key terms used for searching relevant literatures were burden, prevalence, magnitude, malnutrition, nutritional status, under nutrition, low Middle Upper Arm Circumference (MUAC), low Body Mass Index (BMI), protein energy deficiency, pregnant women, associated factors, determinants, predictors, risk factors, causes and Ethiopia. The Preferred Reporting Items for Systematic Reviews and Meta-Analyses Protocols (PRISMA) checklist guidelines[36] was followed to develop this systematic review and meta-analysis.

\section{Eligibility criteria}

\section{Study scope}

all articles which were done in all regional states of Ethiopia till March 2020 on pregnant women nutritional status and its associated factors were included under this review. No restriction was applied to language, study design and setting, study and publication year as well as study participants.

\section{Population}

all reproductive aged women (15-49 years) including adolescents who were pregnant at least once were considered for this review. Studies considered pregnant women with Human Immuno Virus (HIV) as study participants were also included.

\section{Exposure}

all studies examined pregnant women nutritional status and its associated factors were included.

\section{Outcome variable}

studies which measured the outcome of variables using MUAC or BMI during pregnancy were included for this review.

All identified studies titles and abstracts were screened for eligibility criteria of the review. According to selection criteria, full texts of eligible studies were examined. Those papers which did not fully accessed at the time of search process were excluded after contact was attempted with the principal investigator through email at least two times. Finally, after reviewing their full texts, studies which did not report outcome of interest and studies with poor quality as per settled criteria of reviewing the articles were excluded from the final analysis. 


\section{Data extraction}

After standardized data extraction format developed according to 2014 Joanna Briggs Institute Reviewers' Manual [37], the data were extracted using the excel spread sheet. The developed data extraction format includes: author name, publication year, study region or area, study setting, study design, sampling technique, criteria to define malnutrition during pregnancy and its cutoff of point, study participants, sample size, mean age of respondent, response rate and prevalence of under nutrition pregnant women. Factors also systematically extract using cross tabulation between outcome variable and potential associated factors listed in original studies (including age (below 20 vs above 20), income (<1000 vs $\geq 1000$ ), residence (rural vs urban), marital status (unmarried vs married), educational status for both maternal and husband (illiterate vs formal education), women decision (low vs moderate and above), substance abuse (yes vs no), water source (unprotected vs protected), toilet possession (no vs yes), family size ( $\geq 4$ vs $<4$ ), dietary diversity (poor vs good), number of meal (<3 vs $\geq 3$ ), dietary advice (no vs yes), family planning (no vs use), pregnancy intention (unplanned vs planned), antenatal care follow up (no vs yes), parity (nulliparous vs others), gestational age (second and third trimester vs first trimester), any illness (yes vs no) and iron supplementation (no vs yes).

\section{Quality assessment}

Newcastle-Ottawa quality assessment scale adapted for observational studies was used for critical appraisal [38, 39]. The scale is used to score the articles under three categories with total score range $0-10$. The first part is selection (score $0-5$ ): focuses on the methodological quality of each study which includes representativeness of the sample, the sample size, non-respondents and ascertainment of the exposure. The second section is comparability (score 0-2): considers the comparability of different outcome groups in the study based on the study design and analysis in which confounding factors are controlled (i.e. the study controls for the most important factor and the study control for any additional factor). The last section of the tool is about outcomes (0-3): deal about the assessment of the outcome (include independent blind assessment, record linkage and self-report) and statistical analysis of the original study (i.e. the statistical test used to analyze the data is clearly described and appropriate, and measure of association is presented, including $\mathrm{Cl}$ and p-value). After the quality of eligible original articles critically assessed, studies scored half and above out of ten were considered for final analysis. Three identified articles were scored below five and excluded from the final analysis.

Methodological quality and risk of bias in the studies were assessed and evaluated using the 10-item rating scale developed Hoy et al. for prevalence studies (Appendex-1)[40]. Sampling, data collection, reliability and validity of study tools, case definition, and prevalence periods were included in the tool. The rating scale categorized as having low risk of bias ("yes" answers to domain questions) or high risk of bias ("no" answers to domain questions) for each articles. Each study was assigned a score of 1 (Yes) or 0 (No) for each domain, and these scores were summed to provide an overall study quality score. Scores of 8-10 were considered as having a "low risk of bias", 6-7 a "moderate risk", and 0-5 a "high risk".

\section{Outcome measurement}

The first outcome of this systematic review and meta-analysis was the pooled burden of malnutrition among pregnant women in Ethiopia. Malnutrition among pregnant women can be measured using MUAC or BMI. The second outcome of this review was to identify predictors of malnutrition during pregnancy. Factors including: age, income, residence, marital status, educational status, women decision, substance abuse, water source, toilet possession, family size, dietary diversity, number of meal, dietary advice, family planning, pregnancy intention, antenatal care follow up, parity, gestational age, any illness and iron supplementation were considered for this review.

\section{Data analysis}

First the extracted data were computed in excel spread sheet then imported to STATA version 14 for further analysis. Cochran's Q statistic with inverse variance $\left(\mathrm{I}^{2}\right)$ were used to assess the existence of statistical heterogeneity and to quantify it. Low, moderate and high heterogeneity were considered at $25 \%, 50 \%$ and $75 \%$ respectively [41]. In addition, p value less than 0.05 was used to confirm the presence of heterogeneity across studies. Publication bias was assessed using Egger's regression test [42] and funnel plot. The estimated pooled burden of malnutrition and its predictors among pregnant women was presented using forest plot diagram with their corresponding $95 \% \mathrm{Cl}$ and $\mathrm{OR}$. In addition, subgroup analysis and meta-regression were also computed to explore those potential sources of heterogeneity across studies. Those potential factors listed above were analyzed.

\section{Results}

\section{Explanation for original studies}

For this review, a total of 874 articles were searched from major medical electronic data bases and other sources. Because of duplication, 456 articles were excluded. Then after screening, 379 studies were excluded because of inconsistent with our review. The remaining 39 studies full text were assessed based on eligibility criteria and 12 articles were removed because of irrelevancy (Fig- 1 ). Moreover, 27 full articles were critical appraised using Newcastle-Ottawa quality assessment scale. After critical appraisal, three articles [43-45] were excluded because of poor methodological quality scored. Finally, to estimate pooled prevalence of malnutrition and its predictors among pregnant women in Ethiopia, 24 studies were considered (Fig-1). From the included articles, 23 of them were published from 2012 to 2019 whereas one of them was un-published article. These articles were from six regional state and two cities of Ethiopia. Eight studies were done in Oromo regional state [25, 26, 28, 30, 31, 33,

Page $4 / 19$ 
46, 47], six articles in Amhara region [32, 48-52], four articles from South Nation and Nationality of People (SNNP) [27, 34, 53, 54], two articles in Tigray [29, 55] and in Addis Ababa (AA) [56], Dire Dawa [57], Gambella [58] and Ethiopian Somalia [59] shared single articles for each.

In regarding to criteria to classify as malnutrition, $87.5 \%$ of the included articles use MUAC [25, 27-33, 35, 46, 48-54, 56-59] and the remaining $12.5 \%$ of the extracted studies use BMI (below $18.5 \mathrm{~kg} / \mathrm{cm}^{2}$ ) $[26,47,55]$. Those studies which used MUAC, six of them considered malnutrition when MUAC below $21 \mathrm{~cm}$, nine of them considered it when MUAC below $22 \mathrm{~cm}$ whereas the rest six considered when MUAC below $23 \mathrm{~cm}$.

Concerning to study design, $91.6 \%$ of the included articles were cross sectional design [26-33, 35, 46-51, 53-59] and the rest were cohort [25] and case control [52], single article for each. Thirteen studies were done institutional based while the remaining eleven were done in community. 
Table 1

Descriptive summary of 24 studies included in the review of predictors of malnutrition among pregnant women in Ethiopia 2012-2019

\begin{tabular}{|c|c|c|c|c|c|c|c|c|c|c|}
\hline Author & $\begin{array}{l}\text { Publication } \\
\text { year }\end{array}$ & Region & Criteria & $\begin{array}{l}\text { Cutoff } \\
\text { point }\end{array}$ & Study design & $\begin{array}{l}\text { Study } \\
\text { setting }\end{array}$ & $\begin{array}{l}\text { Sample } \\
\text { size }\end{array}$ & $\begin{array}{l}\text { Prevalence } \\
\%\end{array}$ & $\begin{array}{l}\text { Study } \\
\text { participants }\end{array}$ & $\begin{array}{l}\text { NOSS } \\
\text { score }\end{array}$ \\
\hline Derso et al & 2017 & Amhara & MUAC & $<23$ & Crosssectional & Institution & 348 & 35.8 & $\begin{array}{l}\text { Reproductive } \\
\text { age }\end{array}$ & 6 \\
\hline $\begin{array}{l}\text { Dadi AF et } \\
\text { al }\end{array}$ & 2019 & Amhara & MUAC & $<22$ & Crosssectional & Community & 940 & 14.4 & $\begin{array}{l}\text { Reproductive } \\
\text { age }\end{array}$ & 6 \\
\hline $\begin{array}{l}\text { Belete Y et } \\
\text { al }\end{array}$ & 2016 & Oromo & MUAC & $<22$ & Crosssectional & Community & 424 & 34 & Adolescent & 6 \\
\hline Behailu Z & Un-p & AA & MUAC & $<23$ & Crosssectional & Institution & 342 & 34.2 & HIV positive & 5 \\
\hline Asefa et al & 2012 & Oromo & MUAC & $<23$ & Cohort & Institution & 956 & 47.2 & $\begin{array}{l}\text { Reproductive } \\
\text { age }\end{array}$ & 8 \\
\hline $\begin{array}{l}\text { Alemayehu } \\
\text { A et al }\end{array}$ & 2016 & Somalia & MUAC & $<21$ & Crosssectional & Institution & 360 & 18.9 & $\begin{array}{l}\text { Reproductive } \\
\text { age }\end{array}$ & 5 \\
\hline $\begin{array}{l}\text { Diddana } \\
\text { TZ }\end{array}$ & 2019 & Amhara & MUAC & $<23$ & Crosssectional & Community & 604 & 19.5 & $\begin{array}{l}\text { Reproductive } \\
\text { age }\end{array}$ & 7 \\
\hline $\begin{array}{l}\text { Kumera G } \\
\text { et al }\end{array}$ & 2018 & Amhara & MUAC & $<22$ & Crosssectional & Institution & 409 & 16.2 & $\begin{array}{l}\text { Reproductive } \\
\text { age }\end{array}$ & 6 \\
\hline $\begin{array}{l}\text { Kefiyalew } \\
\text { et al }\end{array}$ & 2014 & Oromo & $\mathrm{BMI}$ & $<18.5$ & Crosssectional & Institution & 258 & 11.62 & $\begin{array}{l}\text { Reproductive } \\
\text { age }\end{array}$ & 5 \\
\hline Kedir et al & 2014 & Oromo & MUAC & $<22$ & Crosssectional & Community & 1802 & 19.06 & $\begin{array}{l}\text { Reproductive } \\
\text { age }\end{array}$ & 7 \\
\hline $\begin{array}{l}\text { Hailu S et } \\
\text { al }\end{array}$ & 2019 & Oromo & MUAC & $<21$ & Crosssectional & Institution & 422 & 47 & $\begin{array}{l}\text { Reproductive } \\
\text { age }\end{array}$ & 7 \\
\hline $\begin{array}{l}\text { Hadgu et } \\
\text { al }\end{array}$ & 2013 & Tigray & $\mathrm{BMI}$ & $<18.5$ & Crosssectional & Institution & 376 & 42.3 & HIV positive & 5 \\
\hline $\begin{array}{l}\text { Gizahewu } \\
\text { A et al }\end{array}$ & 2019 & SNNPR & MUAC & $<22$ & Crosssectional & Institution & 211 & 24.6 & $\begin{array}{l}\text { Reproductive } \\
\text { age }\end{array}$ & 5 \\
\hline Gebre et al & 2018 & Oromo & MUAC & $<21$ & Crosssectional & Community & 900 & 24 & $\begin{array}{l}\text { Reproductive } \\
\text { age }\end{array}$ & 7 \\
\hline $\begin{array}{l}\text { Endalifer } \\
\text { et al }\end{array}$ & 2019 & Tigray & MUAC & $<22$ & Crosssectional & Institution & 321 & 22.3 & $\begin{array}{l}\text { Reproductive } \\
\text { age }\end{array}$ & 6 \\
\hline $\begin{array}{l}\text { Kumera et } \\
\text { al }\end{array}$ & 2018 & Amhara & MUAC & $<22$ & Crosssectional & Institution & 234 & 41 & $\begin{array}{l}\text { Reproductive } \\
\text { age }\end{array}$ & 5 \\
\hline $\begin{array}{l}\text { Shiferaw } \\
\text { et al }\end{array}$ & 2019 & SNNPR & MUAC & $<23$ & Crosssectional & Community & 382 & 44.9 & $\begin{array}{l}\text { Reproductive } \\
\text { age }\end{array}$ & 6 \\
\hline $\begin{array}{l}\text { Shenka et } \\
\text { al }\end{array}$ & 2018 & $\begin{array}{l}\text { Dire } \\
\text { Dawa }\end{array}$ & MUAC & $<22$ & Crosssectional & Institution & 387 & 18.2 & $\begin{array}{l}\text { Reproductive } \\
\text { age }\end{array}$ & 6 \\
\hline $\begin{array}{l}\text { Serbesa et } \\
\text { al }\end{array}$ & 2019 & Oromo & $\mathrm{BMI}$ & $<18.5$ & Crosssectional & Institution & 304 & 30.3 & $\begin{array}{l}\text { Reproductive } \\
\text { age }\end{array}$ & 6 \\
\hline $\begin{array}{l}\text { Regassa et } \\
\text { al }\end{array}$ & 2012 & SNNPR & MUAC & $<22$ & Crosssectional & Community & 1094 & 31.4 & $\begin{array}{l}\text { Reproductive } \\
\text { age }\end{array}$ & 7 \\
\hline $\begin{array}{l}\text { Nigatu et } \\
\text { al }\end{array}$ & 2018 & Gambella & MUAC & $<21$ & Crosssectional & Community & 338 & 28.6 & $\begin{array}{l}\text { Reproductive } \\
\text { age }\end{array}$ & 6 \\
\hline $\begin{array}{l}\text { Mariyam } \\
\text { AF et al }\end{array}$ & 2018 & Oromo & MUAC & $<21$ & Crosssectional & Community & 616 & 31.8 & $\begin{array}{l}\text { Reproductive } \\
\text { age }\end{array}$ & 7 \\
\hline $\begin{array}{l}\text { Tadesse et } \\
\text { al }\end{array}$ & 2017 & Amhara & MUAC & $<23$ & Case control & Community & 448 & 30.35 & $\begin{array}{l}\text { Reproductive } \\
\text { age }\end{array}$ & 8 \\
\hline $\begin{array}{l}\text { Moges et } \\
\text { al }\end{array}$ & 2015 & SNNPR & MUAC & $<21$ & Crosssectional & Community & 417 & 35.5 & $\begin{array}{l}\text { Reproductive } \\
\text { age }\end{array}$ & 6 \\
\hline
\end{tabular}

In addition, eleven articles employed simple random technique to select study participants while seven of them used systematic random sampling whereas cluster and consecutive sampling method reported by two articles for each. A total of 12,893 pregnant women were included in this review. $87.5 \%$ of the included articles done on reproductive aged pregnant women $[25-27,29-33,35,46-54,57-59]$ where as $8.3 \%$ of the articles done on 
HIV positive reproductive aged pregnant women $[55,56]$ and single study conducted among adolescent aged pregnant women [28]. All included articles had $95 \%$ and above response rate (Table-1).

In regarding risk bias assessment, 19 (79\%) studies had high quality scores and 5 (21\%) had low quality scores. Representation and case-definition biases were the most commonly noted. To determine the influence of low methodological quality/high risk of bias on our estimates of pooled prevalence we estimated pooled prevalence without the low-quality studies. The confidence intervals of our estimates of pooled prevalence with and without these studies overlapped, indicating no significant difference between them. These results suggest that the majority of the primary study authors have met high quality standards. This lends credibility to our findings (Appendix-1).

\section{Pooled prevalence of malnutrition among pregnant women in Ethiopia}

The pooled burden of malnutrition among pregnant women in Ethiopia was $29.07 \%$ (95\% Cl: 24.84, 33.30) (Fig-2). Even though there was incompatible use of criteria to classify malnutrition among pregnant women, the pooled burden were almost consistent. The pooled estimate of malnutrition among studies which considered MUAC was $29.2 \% 95 \% \mathrm{Cl}$ : 24, 33. Whereas among studies which used BMI was $27.9 \%$ (95\% Cl: 9,46$)$. In this review, $P$ test statistics showed a significant level of heterogeneity $(P=90.6 \%, p<0.001)$. Therefore, to estimate the pooled burden of malnutrition among pregnant women and to examine factors associated with it, random effect model was indicated. In addition, subgroup analysis and meta-regression were employed using different study characteristics to identify potential source of heterogeneity. Furthermore, symmetric funnel plot and Egger's test were undertaken to assess publication bias. But, both of them were failed to indicate observed publication bias (symmetric funnel plot (Fig-3) and Egger's test p-value $=0.439$ (95\% Cl: $0.32,1.545)$.

\section{Subgroup analysis}

Subgroup analysis was done using publication year, region, study design, study setting, sampling technique, classification criteria, study participant and sample size. Regarding to regional burden, one third of pregnant women were suffered from malnutrition in SNNPR and Amhara regional states (33.9\% 95\% Cl: 25, 42 and 30.4\% (95\% Cl: 17, 34 respectively). In Oromo region, 30.4\% (95\% Cl: 21, 39) of pregnant women experienced under nutrition. The pooled prevalence of malnutrition among HIV positive pregnant women was $38.1 \%(95 \% \mathrm{Cl}$ : 30,46$)$ whereas among reproductive aged pregnant women reported $28.2 \%(95 \% \mathrm{Cl}: 23,32)$ of malnutrition. According to publication year, studies published in 2017 and before reported $30.4 \%$ $(95 \% \mathrm{Cl}: 23,37)$ of pooled burden of malnutrition whereas studies published after 2017 evidenced $27.6 \%(95 \% \mathrm{Cl}$ : 22, 33) of malnutrition among pregnant women.

In addition, articles done in cross sectional design reported $28.2 \%(95 \% \mathrm{Cl}: 23,32)$ of pooled burden of malnutrition. But, studies done in cohort and case control indicated $38.6 \%(95 \% \mathrm{Cl}: 22,55)$ of pooled burden of malnutrition. Furthermore, studies selected their study participant using systematic sampling technique showed pooled prevalence of $30.7 \%(95 \% \mathrm{Cl}: 23,38)$ whereas studies used simple random sampling technique evidenced $30.6 \%$ (95\% Cl: 25,35$)$ while studies used cluster and consecutive showed $24.4 \%(95 \% \mathrm{Cl}: 14,34)$ of pooled prevalence of malnutrition among pregnant women in Ethiopia. Ones more, studies with sample size of < 400 reported pooled prevalence of $29.1 \%$ (95Cl: 23,35$)$ and studies which had $>400$ sample size indicated $28.9 \%(95 \% \mathrm{Cl}: 22,35)$ of pooled burden of malnutrition which was almost in line with studies having < 400 sample size (Table-2). 
Table 2

Sub group analysis which describes pooled prevalence of malnutrition among pregnant women with different study characteristics in Ethiopia from 2012-2019

\begin{tabular}{|c|c|c|c|c|c|c|}
\hline Subgroup & & No of studies & prevalence $(95 \% \mathrm{Cl})$ & Heterogeneity statistics & $\mathrm{I}^{2}$ & p-value \\
\hline \multirow[t]{4}{*}{ Region } & Amhara & 6 & $25.9(17,34)$ & 58.34 & 90.4 & $<0.001$ \\
\hline & Oromo & 8 & $30.4(21,39)$ & 108.67 & 91.0 & $<0.001$ \\
\hline & SNNPR & 4 & $33.9(25,42)$ & 64.67 & 89.3 & $<0.001$ \\
\hline & Others & 6 & $27.2(19,34)$ & 17.36 & 82.7 & $<0.001$ \\
\hline \multirow[t]{2}{*}{ Publication year } & 2017 and below & 10 & $30.4(23,37)$ & 116.18 & 90.9 & $<0.001$ \\
\hline & After 2017 & 13 & $27.6(22,33)$ & 120.95 & 89.1 & $<0.001$ \\
\hline \multirow[t]{2}{*}{ Criteria used } & MUAC & 21 & $29.2(24,33)$ & 186.62 & 89.3 & $<0.001$ \\
\hline & BMI & 3 & $27.9(9,46)$ & 52.63 & 94.2 & $<0.001$ \\
\hline \multirow[t]{2}{*}{ Study design } & Cross sectional & 22 & $28.2(23,32)$ & 213.34 & 89.2 & $<0.001$ \\
\hline & Others & 2 & $38.6(22,55)$ & 10.71 & 89.6 & $<0.001$ \\
\hline \multirow[t]{3}{*}{ Sampling technique } & Simple random & 11 & $30.6(25,35)$ & 69.75 & 85.7 & $<0.001$ \\
\hline & Systematic random & 7 & $30.7(23,38)$ & 55.66 & 89.2 & $<0.001$ \\
\hline & Others & 6 & $24.2(14,34)$ & 85.01 & 92.1 & $<0.001$ \\
\hline \multirow[t]{2}{*}{ Study participant } & Reproductive age & 22 & $28.2(23,32)$ & 220.88 & 89.0 & $<0.001$ \\
\hline & HIV patient & 2 & $38.1(30,46)$ & 2.48 & 59.6 & 0.116 \\
\hline \multirow[t]{2}{*}{ Sample size } & $<400$ & 12 & $29.1(23,35)$ & 123.33 & 89.1 & $<0.001$ \\
\hline & $\geq 400$ & 12 & $28.9(22,35)$ & 120.41 & 88.9 & $<0.001$ \\
\hline
\end{tabular}

\section{Meta regression}

In addition to subgroup analysis, meta-regression was done to identify potential source of heterogeneity. Both continuous and categorical study characteristics including: publication year, sample size, mean age of the women, criteria for classification, region, study design and sampling technique were considered. But none of these variables were found to be statistically significant (Table-3). 
Table 3

Meta regression for the included studies to identify potential source of heterogeneity for the pooled burden of malnutrition among pregnant women in Ethiopia 2012-2019

\begin{tabular}{|lll|}
\hline Variables & Coefficients & p-value \\
\hline Study year & 0.3048 & 0.891 \\
\hline Sample size & -0.00087 & 0.941 \\
\hline Mean age & -0.3702 & 0.910 \\
\hline Classification criteria & & \\
\hline MUAC & 1.425 & 0.833 \\
\hline Region & & \\
\hline Amhara & -1.374 & 0.829 \\
\hline SNNPR & 6.773 & 0.348 \\
\hline Oromo & 3.209 & 0.591 \\
\hline Study design & & \\
\hline Cross section & -10.554 & 0.180 \\
\hline Sampling technique & & \\
\hline Simple random & 6.320 & 0.254 \\
\hline Systematic random & 6.470 & 0.287 \\
\hline
\end{tabular}

\section{Predictors of malnutrition among pregnant women in Ethiopia}

In addition to estimating pooled prevalence of malnutrition among pregnant women in Ethiopia, this review also examined the predictors of malnutrition including: maternal age, income, residence, marital status, educational status, women decision, substance abuse, water source, toilet possession, family size, dietary diversity, number of meal, dietary advice, family planning, pregnancy intention, antenatal care follow up, parity, gestational age, any illness and iron supplementation. Among these factors, only maternal education, income, pregnancy intention, number of meal, dietary diversity, antenatal care and iron supplementation were significantly associated with the pooled prevalence of malnutrition among pregnant women in Ethiopia (Fig-4, 5\&6).

The association between maternal education and malnutrition were stated in ten of the included articles [27-31, 33, 48, 54, 56, 57]. The odds of malnutrition was 1.6 times higher among illiterate pregnant women than women who had formal education $(\mathrm{OR}=1.60,95 \% \mathrm{Cl}$ : $1.01,2.53)$.

Monthly family income was another factors significantly associated with malnutrition in which its relation described in five original studies [27, 34 , $47,48,54]$. The likely hood of malnutrition among pregnant women who had monthly income of less than 1000 Ethiopian birr was 3 times higher than their counterparts $(\mathrm{OR}=3.07,95 \% \mathrm{Cl}: 1.36,6.92)($ Fig-4).

This analysis also showed that dietary diversity was significantly associated with the pooled burden of malnutrition among pregnant women which was cited in five of original studies [27, 31, 50, 54, 57]. Pregnant women who recorded as poor dietary diversity were 2.89 times more likely to be malnutrition than pregnant women who had good dietary diversity $(\mathrm{OR}=2.89,95 \% \mathrm{Cl}: 1.28,6.53)$. The overall pooled burden of malnutrition among pregnant women was significantly associated with ante natal care follow up in which its association recorded in five included articles [28, 30,34 , 50 , 54]. The odds of malnutrition were 2.53 times higher among pregnant women who had no ante natal care follow up than pregnant women who had ante natal care follow up $(\mathrm{OR}=2.53,95 \% \mathrm{Cl}$ : $1.18,5.42)$. Moreover, this review found that iron supplementation during pregnancy was protective for malnutrition among pregnant women. Its protective effect was listed in two of the included articles [29, 33]. Pregnant women who supplied with iron during pregnancy were 0.63 times risk of being malnutrition than their counterparts $(\mathrm{OR}=0.63,95 \% \mathrm{Cl}$ : $0.45,0.88)$. So, iron supplementation had $37 \%$ of reduction in risk of malnutrition among pregnant women (Fig-5).

Furthermore, the present review evidenced that number of meal was significantly associated with malnutrition among pregnant women in which its connection stated in three original articles $[27,28,56]$. The odds of malnutrition among pregnant women who had less than tree meal per day was 4.63 times higher than pregnant women who had three and above meal per day (OR $=4.63,95 \% \mathrm{Cl}$ : 3.00 , 7.15$)$. Ones more, the overall pooled burden of malnutrition among pregnant women was significantly associated with pregnancy intention in which its relation listed in three of included studies $[31,48,54]$. The likely hood of malnutrition among pregnant women was 1.33 times higher among women whose pregnancy was planned than pregnant women whose pregnancy was unplanned (OR $=1.33,95 \% \mathrm{Cl}$ : 1.01, 1.37) (Fig-6). 
But, including maternal age, residence, marital status, women decision, substance abuse, water source, toilet possession, family size, dietary advice, family planning, parity, gestational age and illness during pregnancy were not associated with the pooled prevalence of malnutrition among pregnant women.

\section{Discussion}

To the best of my knowledge, this is the first systematic review and meta-analysis done to estimate the predictors of malnutrition among pregnant women in Ethiopia. The present review evidenced, the overall pooled prevalence of malnutrition among pregnant women in Ethiopia was $29.07 \%$ (95\% Cl: 24.84, 33.30). The prevalence and consequences of malnutrition among pregnant women is highly prevalent in developing countries particularly in Sub Saharan Africa (SSA), resulting in substantial increases in mortality and disease burden [19]. As Ethiopia is one of the developing countries, the present review recorded significant number of pregnant women were under nourished. This may be due to the majority of Ethiopian population were rural residence with no formal education, more of adolescent, higher parity status, poor dietary diversity and higher food insecurity, leads to higher risk of malnutrition $[22,46,58,60]$. In addition, the national ante natal care utilization is still poor which will be a constraint to supply iron for pregnant women [60]. Therefore, education for all, utilization of family planning, nutritional intervention and policies and early initiation of ante natal care for all pregnant women as World Health Organization recommended were mandatory to reduce such significant burden of malnutrition among pregnant population in Ethiopia.

The finding of this review was higher than findings of systematic review done in Africa, studies done in Democratic Republic of Congo, Lebanon, Sudan and Sri Lanka which was $23.5 \%, 14 \%, 10.2 \%, 15 \%$ and $5.5 \%$ respectively [61-65]. But, this finding was lower than results of studies conducted in Bangladesh, South India and Kenya which was 59\%, 51\% and 31.7\% respectively [66-68].

In this meta-analysis, predictors of malnutrition among pregnant women in Ethiopia were also assessed. Maternal education, monthly income, dietary diversity, antenatal care, iron supplementation, number of meal and pregnancy intention were predictors of malnutrition among pregnant women in Ethiopia.

According to the present review, maternal education was positively correlated with malnutrition during pregnancy. Illiterate pregnant women were higher odds of malnutrition than women with formal education. This may be due to illiterate women were less likely to understand the benefits of practicing good nutrition for the fetus and herself. They are also at risk for poor dietary practice and poor behavioral modification in terms of eating habit and dietary diversification. Even they may not have enough monthly income for good food diversity and [69]. This figure is in line with systematic review done in Africa and studies done in Pakistan and Bangladesh $[17,61,66]$.

The odds of malnutrition among pregnant women was significantly higher among women who had monthly income of less than 1000 Ethiopian birr. It is evidenced that improved income for the poor family can significantly improve power of purchasing and their food expenditures, enhance their access to health care services, water and sanitation [70]. So, failure to have enough financial incentives for nutrition can lead to long-term economic consequences both at the household and macro-economic level [71]. This finding is supported by studies done in Senegal, Nigeria, Iran and India which evidenced inadequate economic environment leads to malnutrition [70, 72-74]. Education and income are the best means of overcoming cyclic poverty particularly in developing countries where poverty is key factor for malnutrition [75].

In addition, this analysis showed that dietary diversity was significantly associated with maternal nutritional status. The likely hood of malnutrition among pregnant women with poor dietary diversity was higher when compared with pregnant women with good dietary diversity. The possible explanation is having healthy and notorious food are the major requirements to get all essential nutrients. It is evidenced that meeting the recommended dietary diversity prevents under nutrition or associated with nutrient adequacy [76, 77]. So, the less food groups included in a daily diet, the chances of meeting nutrient requirements is low [8]. This result is consistent with study done in Kenya which showed pregnant women with higher dietary diversity were noted with adequate nutritional status [78].

Furthermore, pregnant women had no antenatal care follow up were more likely to be under nourished when compared with women who had antenatal care follow up. This might be explained by getting nutrition information from health professionals and follow the healthy dietary practice is further advocating through antenatal care. Antenatal care is an opportune time to identify women with an "unhealthy" dietary pattern in early pregnancy. Following healthy nutrition further, improve nutrient intake and improve nutritional status [79].

Moreover, this review indicated that iron supplementation during pregnancy reduces risk of malnutrition among pregnant women. This may be evidenced that iron deficiency anemia which is one form of malnutrition, is prevented and treated with iron. It will increase red blood cells, resistance to infection and improve appetites of the pregnant women. All pregnant women should routinely receive iron supplements, together with appropriate dietary advice, to prevent under nutrition $[80,81]$. The odds of malnutrition were higher among pregnant women who had less than three times meal per day than pregnant women who had three and above times meal per day. This may be due to the having less amount of meal will cause unbalanced diet and inadequate nutrient intake leads to protein energy and micro-nutrient deficiency. Improving eating habit in order to maintain the increased demand for nutrients reduced risk of malnutrition among pregnant women [78, 82]. 
Ones more, pregnancy intention was significantly associated with malnutrition during pregnancy. Women who had unplanned pregnancy were more likely to be under nourished than women who had planned pregnancy. This may be due to when women getting pregnancy unplanned, the probability of starting antenatal care early, getting better health and nutritional support is low. This will reduce the health and nutritional care given for themselves and their children leads to poor quality and quantity of foods [83, 84]. Provision of timely high-impact evidence based antenatal care best practices improves health outcomes for mothers and newborns.

Generally, many individual articles done in eight different areas of Ethiopia were included this review to have concrete evidence burden of malnutrition among pregnant women in Ethiopia. This will have great influential impact to carry out those nutritional programs and interventions in order to achieve SDGs leads to prevention and reduction of malnutrition related maternal morbidity and mortality. So, this evidence will be used as baseline for healthy policy makers, planners and implementers.

\section{Study limitation}

Majority of the included articles were cross sectional study design in which the result might potentially affected by confounding variables and difficult to establish temporal relationship between the outcome and exposure variables. In addition, the meta-analysis didn't include all regions of Ethiopia which only includes six regions and two administrative city of the country. Therefore, further country based studies to assess other confounding factors related to health service factors, health policy factors and health care giver related factors is recommended.

\section{Conclusion}

This systematic review and meta-analysis revealed significant number of pregnant women in Ethiopia were suffered from malnutrition. Sociodemographic, dietary habit and pregnancy related factors significantly associated with under nutrition of pregnant women. Illiteracy, monthly income less than 1000 Ethiopian birr, poor dietary diversity, absence of antenatal care, unplanned pregnancy and less than three meal per day were significantly increased malnutrition among pregnant women. Whereas, iron supplementation during pregnancy significantly reduce risk of malnutrition among pregnant women. Therefore, running programs and interventions are needed to allviate such constriants factors. Strategies including empowering women through education, advocatting universal access of antenatal care and family planning service according to the recommendation, economic reforms, promoting iron supplemntation and encouraging pregnant women to have adquate dietary diversity and diet frequency were needed to improve burden of malnutrition among pregnant women in Ethiopia.

\section{Abbreviations}

AA: Addis Ababa, EDHS-Ethiopian Demographic Health Survey, SDG-Sustainable Developmental Goal, SNNP-South Nation and Nationality peoples, SSA-Sub Saharan Africa, WHO-World Health Organization

\section{Declarations}

\section{Acknowledgment}

Not applicable.

\section{Funding}

No funding was obtained for this study.

Availability of data and materials

Data will be available from the corresponding author upon reasonable request.

\section{Author contributions}

TG developed the protocol and involved in the design, selection of study, data extraction, statistical analysis and developing the initial drafts of the manuscript. TG and AN prepared and revising subsequent drafts as well as prepared the final draft of the manuscript. Both authors read and approved the final draft of the manuscript.

\section{Ethics approval and consent to participate}

Not applicable.

\section{Consent for publication}

Not applicable. 
The author have declared that there are no competing interests.

\section{Publisher's Note}

Springer Nature remains neutral with regard to jurisdictional claims in published maps and institutional affiliations.

\section{Author details}

1. Department of Midwifery, College of Health Science, Debre Markos University, P.O BOX 269, Debre Markos, Ethiopia

2. ${ }^{2}$ Department of Human Nutrition and Food Science, College of Health Science, Debre Markos University, Debre Markos, Ethiopia

3. ${ }^{3}$ Center of excellence in Human Nutrition, School of Human Nutrition, Food Science and Technology, Hawassa University, Ethiopia

\section{References}

1. WHO. Global nutrition policy review 2016-2017: country progress in creating enabling policy environments for promoting healthy diets and nutrition. 2018.

2. WHO. Double-duty actions for nutrition: policy brief. In.: World Health Organization; 2017.

3. WHO. The state of food security and nutrition in the world 2018: building climate resilience for food security and nutrition: Food \& Agriculture Org.; 2018.

4. Ahmed T, Hossain M, Sanin KI. Global burden of maternal and child undernutrition and micronutrient deficiencies. Annals of Nutrition Metabolism. 2012;61(Suppl. 1):8-17.

5. WHO. World health statistics 2015: World Health Organization; 2015.

6. Black RE, Allen LH, Bhutta ZA, Caulfield LE, De Onis M, Ezzati M, Mathers C, Rivera J. Maternal, Group CUS: Maternal and child undernutrition: global and regional exposures and health consequences. The lancet. 2008;371(9608):243-60.

7. Black RE, Victora CG, Walker SP, Bhutta ZA, Christian P, De Onis M, Ezzati M, Grantham-McGregor S, Katz J, Martorell R. Maternal and child undernutrition and overweight in low-income and middle-income countries. The lancet. 2013;382(9890):427-51.

8. Lee SE, Talegawkar SA, Merialdi M, Caulfield LE. Dietary intakes of women during pregnancy in low-and middle-income countries. Public Health Nutr. 2013;16(8):1340-53.

9. USAID. Multi-Sectoral Nutrition Strategy Technical Brief: Implementation Guidance for Preventing Child \& Maternal Deaths. 2014.

10. Copelton DA. "You are what you eat": nutritional norms, maternal deviance, and neutralization of women's prenatal diets. Deviant Behavior. 2007;28(5):467-94.

11. WHO. Essential nutrition actions: improving maternal, newborn, infant and young child health and nutrition. 2013.

12. Nnam N: Improving maternal nutrition for better pregnancy outcomes. Proceedings of the Nutrition Society 2015, 74(4):454-459.

13. Woldeamanuel GG, Geta TG, Mohammed TP, Shuba MB, Bafa TA: Effect of nutritional status of pregnant women on birth weight of newboms at Butajira Referral Hospital, Butajira, Ethiopia. SAGE open medicine 2019, 7:2050312119827096.

14. Siza J. Risk factors associated with low birth weight of neonates among pregnant women attending a referral hospital in northern Tanzania. Tanzania journal of health research. 2008;10(1):1-8.

15. Conti J, Abraham S, Taylor A. Eating behavior and pregnancy outcome. J Psychosom Res. 1998;44(3-4):465-77.

16. Black RE. What makes good nutrition so important? The Lancet. 2013;382(9890):427-51.

17. Khalid N, Aslam Z, Kausar F, Irshad H, Anwer P. Maternal malnutrition and its kick on child growth: an alarming trim for Pakistan. J Food Nutr Popul Health. 2017;1(3):24.

18. Global Nutrition Report: From Promise to Impact: Ending Malnutrition by 2030. International Food Policy Research Institute 2016.

19. Bain LE, Awah PK, Geraldine N, Kindong NP, Siga Y, Bernard N, Tanjeko AT. Malnutrition in Sub-Saharan Africa: burden, causes and prospects. Pan African Medical Journal 2013, 15(1).

20. AMON TD. Nutrition during pregnancy in Africa. 2019.

21. Lindsay K, Gibney E, McAuliffe F. Maternal nutrition among women from Sub-Saharan Africa, with a focus on Nigeria, and potential implications for pregnancy outcomes among immigrant populations in developed countries. Journal of human nutrition dietetics. 2012;25(6):534-46.

22. FDRE. Ethiopian Demographic and Health Survey 2016.

23. Branca F, Grummer-Strawn L, Borghi E, Blössner Md. Onis Md: Extension of the WHO maternal, infant and young child nutrition targets to 2030. SCN News 2015(41):55-58.

24. UNSCN. Nutrition and the Post-2015 Sustainable Development Goals. 2014.

Page 12/19 
25. Assefa N, Berhane Y, Worku A. Wealth status, mid upper arm circumference (MUAC) and antenatal care (ANC) are determinants for low birth weight in Kersa, Ethiopia. PloS one 2012, 7(6).

26. Kefiyalew F, Zemene E, Asres Y, Gedefaw L. Anemia among pregnant women in Southeast Ethiopia: prevalence, severity and associated risk factors. BMC Res Notes. 2014;7(1):771.

27. Addisalem G, Bruke BB, Mouaz AY. Under Nutrition and Associated Factors among Pregnant Women at ANC Clinic, Nigist Eleni Mohammad Memorial General Hospital, Hossana, Southern Ethiopia. Food Nutr Current Res. 2019;2(2):158-65.

28. Belete Y, Negga B, Firehiwot M. Under nutrition and associated factors among adolescent pregnant women in Shashemenne District, West Arsi Zone, Ethiopia: a community-based. Journal of Nutrition Food Sciences. 2016;6(1):1-7.

29. Endalifer M, Tewabe M, Adar A. Undernutrition and associated factors among pregnant women attending ANC follow up in Alamata general hospital, Northern Region, Ethiopia, 2017. J Nutr Health Food Eng. 2019;9(3):70-8.

30. Gebre B, Biadgilign S, Taddese Z, Legesse T, Letebo M. Determinants of malnutrition among pregnant and lactating women under humanitarian setting in Ethiopia. BMC Nutrition. 2018;4(1):11.

31. Kedir H, Berhane $\mathrm{Y}$, Worku A: Magnitude and determinants of malnutrition among pregnant women in eastern $E$ thiopia: evidence from rural, community-based setting. Maternal \& child nutrition 2016, 12(1):51-63.

32. Kumera G, Gedle D, Alebel A, Feyera F, Eshetie S: Undernutrition and its association with socio-demographic, anemia and intestinal parasitic infection among pregnant women attending antenatal care at the University of Gondar Hospital, Northwest Ethiopia. Maternal health, neonatology and perinatology 2018, 4(1):18.

33. Mariyam A, Dibaba B. Epidemiology of malnutrition among pregnant women and associated factors in central refit valley of Ethiopia, 2016. Journal of Nutritional Disorders Therapy. 2018;8(1):2161-0509.1000222.

34. Moges A, Gudina E, Yadeta D: Under nutrition and Associated Factors among Adolescent Pregnant Women in Afdem district, Ethiopian Somali Region, Eastern Ethiopia. Harmaya University; 2017.

35. Moges M, Worku A, Loha E. Nutritional status and associated factors among pregnant women in Boricha Woreda, Sidama Zone, Southern Ethiopia. European Journal of Nutrition \& Food Safety 2015:386-386.

36. Liberati A, Altman DG, Tetzlaff J. "The PRISMA statement for reporting systematic reviews and meta-analyses of studies that evaluate health care interventions: explanation and elaboration," Journal of Clinical Epidemiology 2009, 62(10).

37. Munn Z, Moola S, Lisy K, D R: The Joanna Briggs institute reviewers' manual 2014. The systematic review of prevalence and incidence data. Adelaide:. The Joanna Briggs Institute 2014.

38. Herzog R, Álvarez-Pasquin MJ, Díaz C, Del Barrio JL, Estrada JM. Á G: Are healthcare workers' intentions to vaccinate related to their knowledge, beliefs and attitudes? A systematic review. BMC Public Health 2013, 13(1).

39. Wells G, Shea B, O'Connell D, Peterson J, Welch V, Losos M: The Newcastle-Ottawa (NOS) for assessing the quality of nonrandomized studies in meta-analysis. Ottawa:. Ottawa Hospital Research Institute 2017.

40. Hoy D, Brooks P, Woolf A, Blyth F, March L, Bain C. ea: Assessing risk of bias in prevalence studies: modification of an existing tool and evidence of interrater agreement.. J Clin Epidemiol. 2012;65(9):934-9.

41. Huedo-Medina TB, Sánchez-Meca J, Marín-Martínez F, Botella J. Assessing heterogeneity in meta-analysis: Q statistic or I² index? Psychol Methods. 2006;11(2):193.

42. G. R-G: Detecting publication bias in random effects meta-analysis:. An empirical comparison of statistical methods 2006.

43. Kuche D, Singh P, Moges D, Belachew T. Nutritional status and associated factors among pregnant women in Wondo Genet District, Southern Ethiopia. JFSE. 2015;5:85-94.

44. Melku M, Addis Z, Alem M, Enawgaw B: Prevalence and predictors of maternal anemia during pregnancy in Gondar, Northwest Ethiopia: an institutional based cross-sectional study. Anemia 2014, 2014.

45. Sonko A. Assessment of dietary practice and anthropometric status of pregnant women in Aleta Chuko Woreda Southern Nations, Nationalities and People's Region/SNNPR/, Ethiopia. J Epidemiol Public Health Rev. 2016;1(1):1-9.

46. Hailu S, Woldemichael B. Dietary diversity and associated factors among pregnant women attending antenatal care at public health facilities in Bale Zone, Southeast Ethiopia. Nutrition Dietary Supplements. 2019;11:1.

47. Serbesa ML, Iffa MT, Geleto M: Factors associated with malnutrition among pregnant women and lactating mothers in Miesso Health Center, Ethiopia. 2019.

48. Dadi AF, Desyibelew HD. Undernutrition and its associated factors among pregnant mothers in Gondar town, Northwest Ethiopia. PloS one $2019,14(4)$.

49. Derso T, Abera Z, Tariku A. Magnitude and associated factors of anemia among pregnant women in Dera District: a cross-sectional study in northwest Ethiopia. BMC Res Notes. 2017;10(1):359.

50. Diddana TZ. Factors associated with dietary practice and nutritional status of pregnant women in Dessie town, northeastern Ethiopia: a community-based cross-sectional study. BMC Pregnancy Childbirth. 2019;19(1):517.

Page 13/19 
51. Kumera G, Haile K, Abebe N, Marie T, Eshete T. Anemia and its association with coffee consumption and hookworm infection among pregnant women attending antenatal care at Debre Markos Referral Hospital, Northwest Ethiopia. PloS one 2018, 13(11).

52. Tadesse SE, Seid O, G/Mariam Y, Fekadu A, Wasihun Y, Endris K, Bitew A. Determinants of anemia among pregnant mothers attending antenatal care in Dessie town health facilities, northern central Ethiopia, unmatched case-control study. PloS one. 2017;12(3):e0173173.

53. Regassa N, Stoecker BJ. Contextual risk factors for maternal malnutrition in a food-insecure zone in southern Ethiopia. J Biosoc Sci. 2012;44(5):537-48.

54. Shiferaw A, Husein G. Acute Under Nutrition and Associated Factors among Pregnant Women in Gumay District, Jimma Zone, South West Ethiopia. J Women's Health Care. 2019;8(459):2167-0420.1000459.

55. Hadgu TH, Worku W, Tetemke D, Berhe H. Undernutrition among HIV positive women in Humera hospital, Tigray, Ethiopia, 2013: antiretroviral therapy alone is not enough, cross sectional study. BMC Public Health. 2013;13(1):943.

56. Behailu Z: Malnutrition among HIV-positive pregnant women; magnitude and determinants, in health centers of Addis Ababa Ethiopia. Addis Ababa Universty; 2018.

57. Shenka A, Damena M, Abdo M, Roba KT. Dietary Diversity and Nutritional Status of Pregnant Women Attending Public Hospitals in Dire Dawa City Administration, Eastern Ethiopia. East African Journal of Health Biomedical Sciences. 2018;2(1):10-7.

58. Nigatu M, Gebrehiwot TT, Gemeda DH: Household Food Insecurity, Low Dietary Diversity, and Early Marriage Were Predictors for Undernutrition among Pregnant Women Residing in Gambella, Ethiopia. Advances in Public Health 2018, 2018.

59. Alemayehu A, Gedefaw L, Yemane T, Asres Y: Prevalence, severity, and determinant factors of Anemia among pregnant women in south Sudanese refugees, Pugnido, Western Ethiopia. Anemia 2016, 2016.

60. Indicators. Key Ethiopian Mini Demographic and Health Survey. 2019.

61. Desyibelew HD, Dadi AF: Burden and determinants of malnutrition among pregnant women in Africa: A systematic review and meta-analysis. Plos one 2019, 14(9).

62. Landis S, Lokomba V, Ananth C, Atibu J, Ryder R, Hartmann K, Thorp J, Tshefu A, Meshnick S. Impact of maternal malaria and under-nutrition on intrauterine growth restriction: a prospective ultrasound study in Democratic Republic of Congo. Epidemiology Infection. 2009;137(2):294304.

63. Zgheib C, Matta J, Sacre Y. Evaluation of Food Behaviour and Nutritional Status of Pregnant Women Resident in Keserwan. J Preg Child Health. 2017;4(331):2.

64. Elmugabil A, Rayis DA, Abdelmageed RE, Adam I, Gasim GI. High level of hemoglobin, white blood cells and obesity among Sudanese women in early pregnancy: a cross-sectional study. Future science OA. 2017;3(2):FSO182.

65. Adikari A, Sivakanesan R, Wijesinghe D, Liyanage C. Assessment of nutritional status of pregnant women in a rural area in Sri Lanka. 2016.

66. Hossain B, Sarwar T, Reja S, Akter M. Nutritional status of pregnant women in selected rural and urban area of Bangladesh. J Nutr Food Sci. 2013;3(4):1-3.

67. Lukose A, Ramthal A, Thomas T, Bosch R, Kurpad AV, Duggan C, Srinivasan K. Nutritional factors associated with antenatal depressive symptoms in the early stage of pregnancy among urban South Indian women. Matern Child Health J. 2014;18(1):161-70.

68. Kemunto ML: Dietary Diversity and Nutritional Status of Pregnant Women Aged 15-49 Years Attending Kapenguria District Hospital West Pokot County. Kenya kenayatta University Institutional Repository 2013.

69. Dunneram Y, Jeewon R. Healthy diet and nutrition education program among women of reproductive age: a necessity of multilevel strategies or community responsibility. Health promotion perspectives. 2015;5(2):116.

70. Oh H-K, Kang S, Cho S-H, Ju Y-j, Faye D. Factors influencing nutritional practices among mothers in Dakar, Senegal. PloS one 2019, 14(2).

71. Biadgilign S, Shumetie A, Yesigat H. Does Economic Growth Reduce Childhood Undernutrition in Ethiopia? PloS one 2016, 11(8).

72. Vakili M, Abedi P, Sharifi M, Hosseini M. Dietary diversity and its related factors among adolescents: a survey in Ahvaz-Iran. Global journal of health science. 2013;5(2):181.

73. Mahanta LB, Roy TD, Dutta RG, Devi A. Nutritional status and the impact of socioeconomic factors on pregnant women in Kamrup district of Assam. Ecology of food nutrition. 2012;51(6):463-80.

74. Adinma J, Umeononihu O, Umeh M. Maternal nutrition in Nigeria. Tropical Journal of Obstetrics Gynaecology. 2017;34(2):79-84.

75. Howard M, Millard AV: Hunger and shame: Child malnutrition and poverty on Mount Kilimanjaro: Routledge; 2012.

76. Adubra L, Savy M, Fortin S, Kameli Y, Kodjo NE, Fainke K, Mahamadou T, Le Port A, Martin-Prével Y. The Minimum Dietary Diversity for Women of Reproductive Age (MDD-W) indicator is related to household food insecurity and farm production diversity: evidence from rural Mali. Current developments in nutrition. 2019;3(3):nzz002.

77. Desta M, Akibu M, Tadese M, Tesfaye M: Dietary Diversity and Associated Factors among Pregnant Women Attending Antenatal Clinic in Shashemane, Oromia, Central Ethiopia: A Cross-Sectional Study. Journal of nutrition and metabolism 2019, 2019.

78. Kiboi W, Kimiywe J, Chege P. Dietary diversity, nutrient intake and nutritional status among pregnant women in Laikipia County, Kenya. International Journal of Health Sciences \& Research 2016:378-379.

Page 14/19 
79. Ghosh-Jerath S, Devasenapathy N, Singh A, Shankar A, Zodpey S. Ante natal care (ANC) utilization, dietary practices and nutritional outcomes in pregnant and recently delivered women in urban slums of Delhi, India: an exploratory cross-sectional study. Reproductive health. 2015;12(1):20.

80. Imdad A, Bhutta ZA. Routine iron/folate supplementation during pregnancy: effect on maternal anaemia and birth outcomes. Paediatr Perinat Epidemiol. 2012;26:168-77.

81. Stoltzfus RJ, Dreyfuss ML: Guidelines for the use of iron supplements to prevent and treat iron deficiency anemia, vol. 2: Ilsi Press Washington, DC; 1998.

82. Toselli S, Argnani L, Canducci E, Ricci E, Gualdi-Russo E. Food habits and nutritional status of adolescents in Emilia-Romagna, Italy. Nutricion hospitalaria. 2010;25(4):613-21.

83. Wado YD, Afework MF, Hindin MJ. Effects of maternal pregnancy intention, depressive symptoms and social support on risk of low birth weight: a prospective study from southwestern Ethiopia. PloS one 2014, 9(5).

84. Abame DE, Abera M, Tesfay A, Yohannes Y, Ermias D, Markos T, Goba G. Relationship Between Unintended Pregnancy and Antenatal Care Use During Pregnancy in Hadiya Zone, Southern Ethiopia. Journal of reproduction infertility. 2019;20(1):42.

\section{Figures}

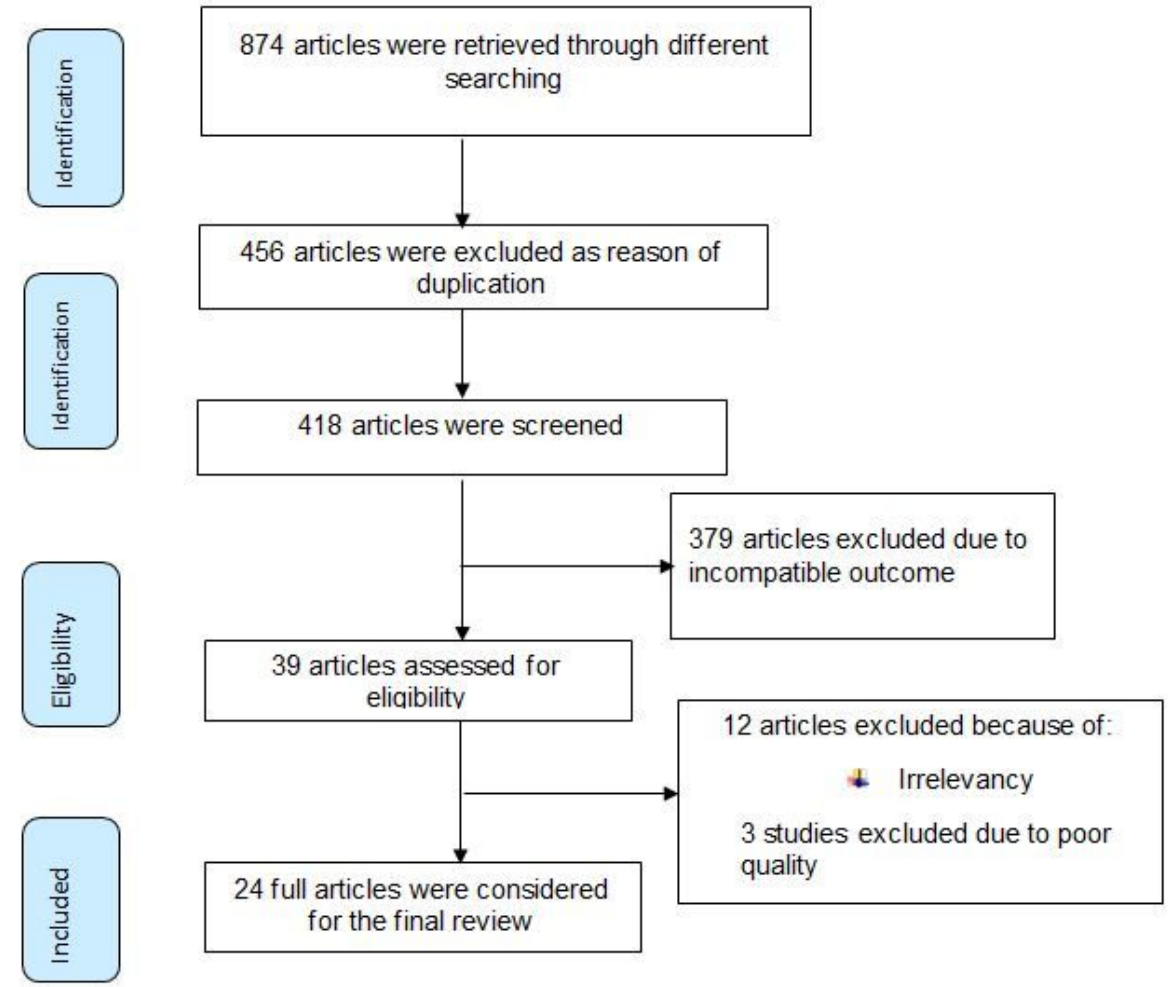

Figure 1

PRISMA flow diagram of included studies to estimate pooled prevalence of burden of under-nutrition and its associated factors among pregnant women in Ethiopia 


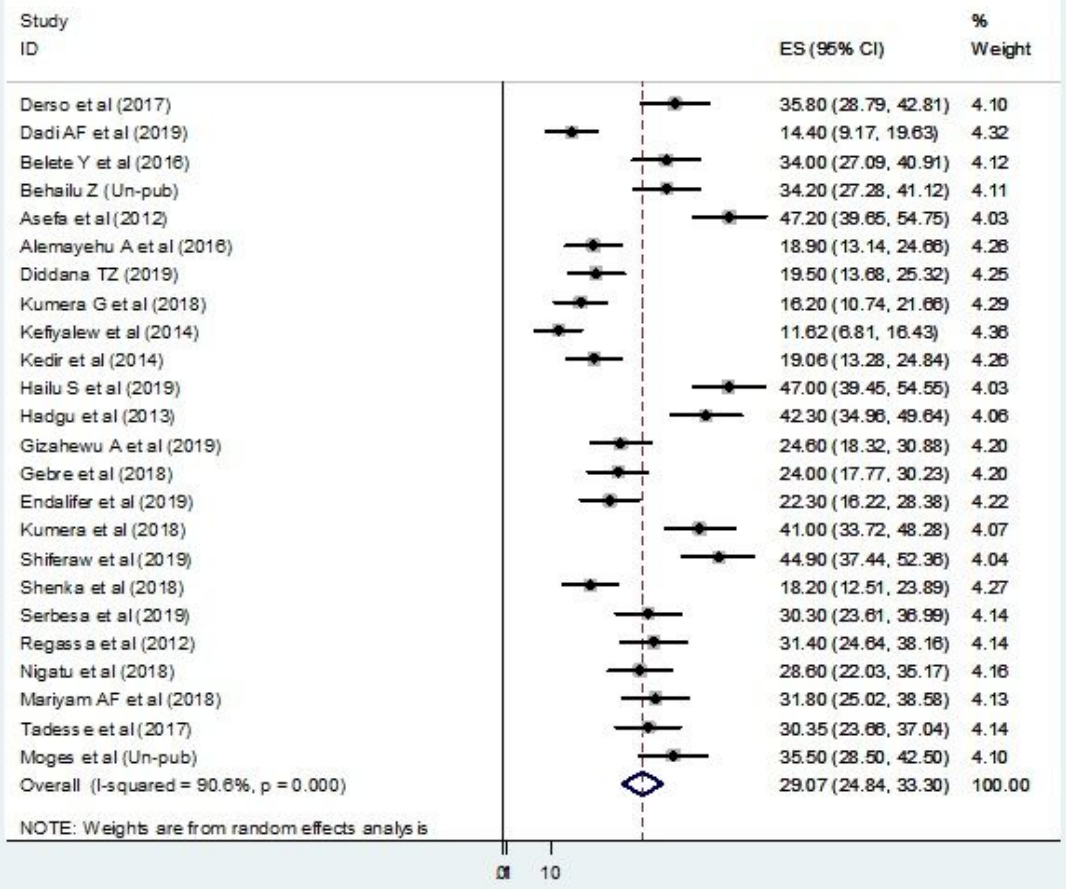

\section{Figure 2}

Forest plot of the pooled prevalence of malnutrition among pregnant women in Ethiopia from 2012-2019

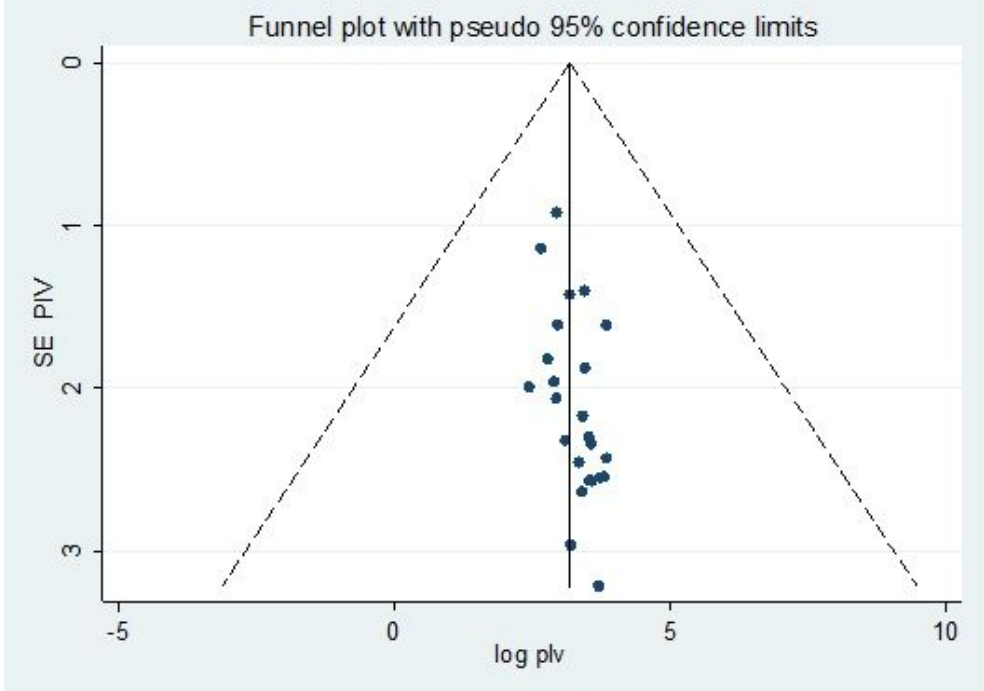

\section{Figure 3}

Meta funnel presentation of predictors of malnutrition among pregnant women in Ethiopia from 2012-2019 


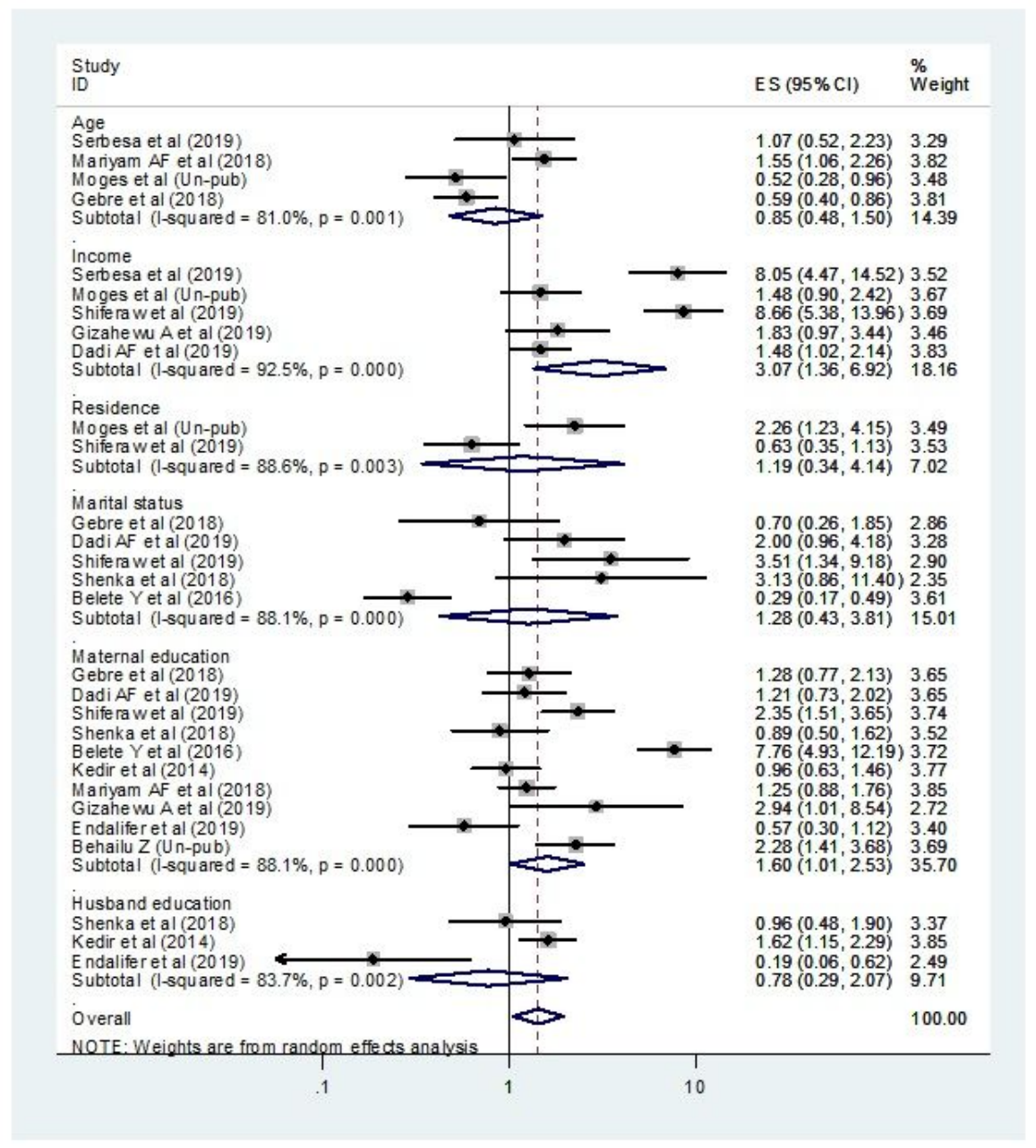

Figure 4

Forest plots which describe association of educational status, residence, income, age and marital status with pooled burden of malnutrition among pregnant women in Ethiopia 2012-2019 


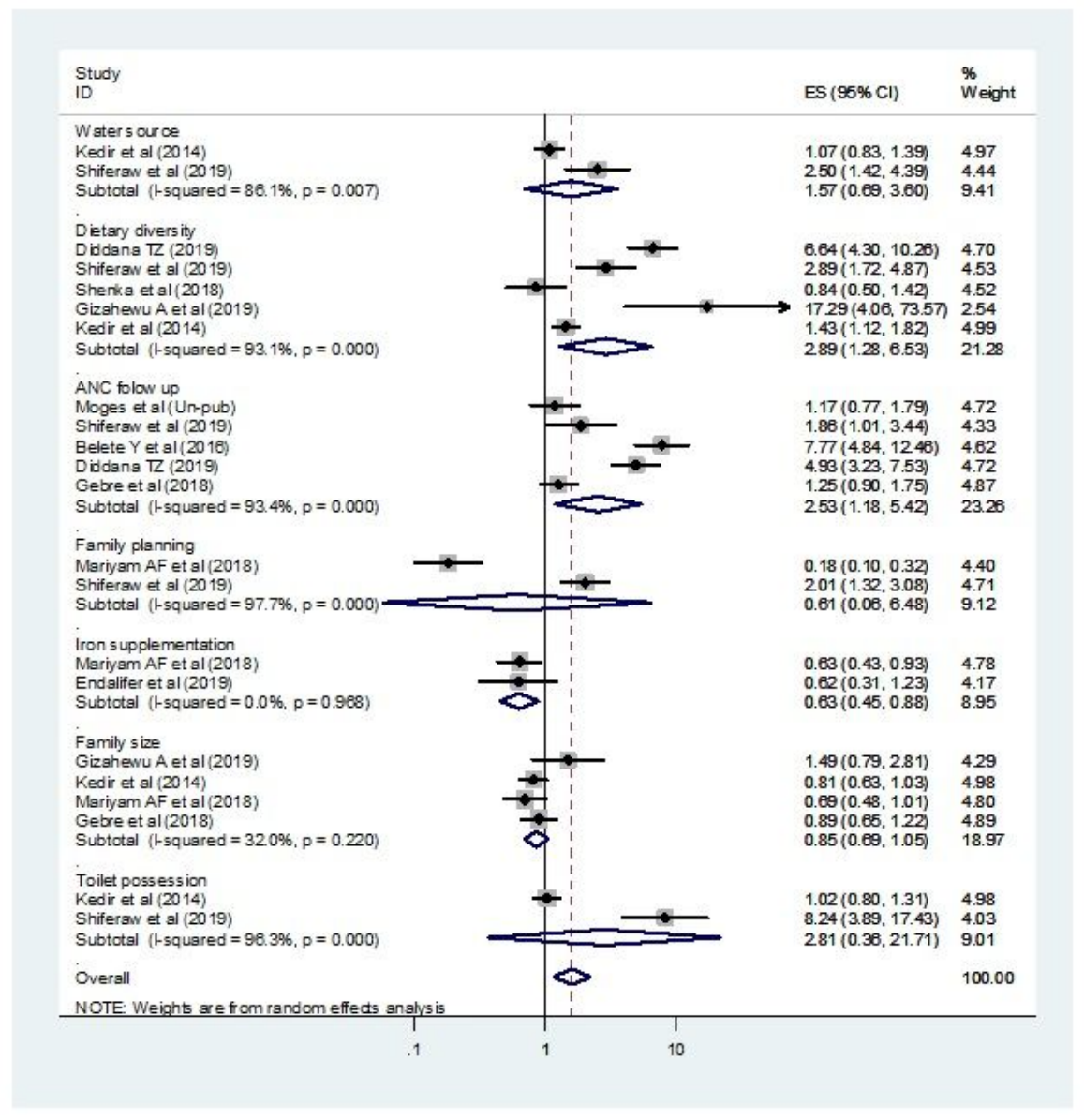

\section{Figure 5}

Forest plots which describe association of water source, dietary diversity, ANC, family planning, iron supplementation, family size and toilet possession with pooled burden of malnutrition among pregnant women in Ethiopia 2012-2019 


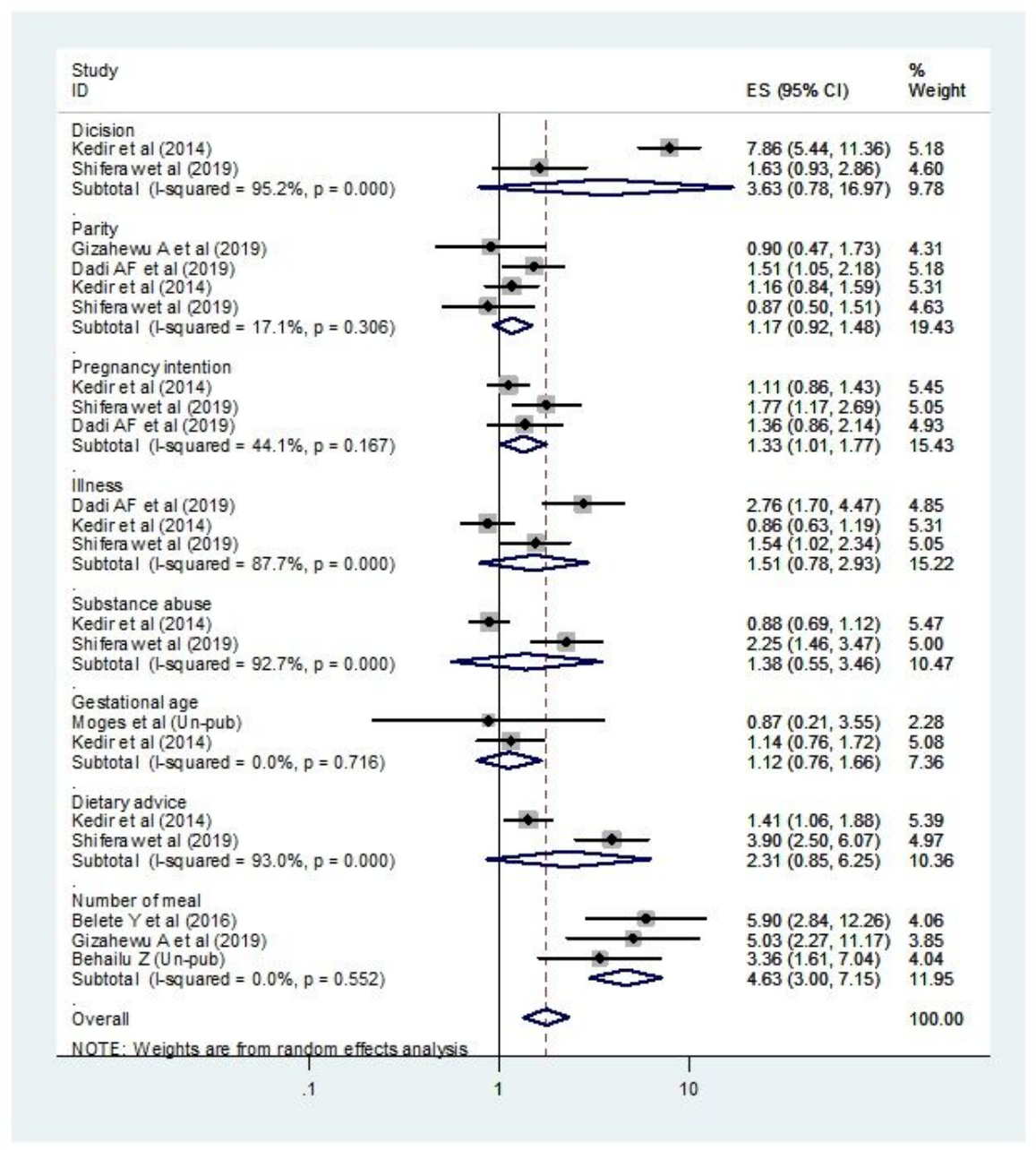

Figure 6

Forest plots which describe association of decision, pregnancy intention, parity, illness, substance abuse, gestational age, dietary advice and number of meal with pooled burden of malnutrition among pregnant women in Ethiopia 2012-2019

\section{Supplementary Files}

This is a list of supplementary files associated with this preprint. Click to download.

- INFDD1800457prismachecklist.doc

- Appendix1.xlsx 